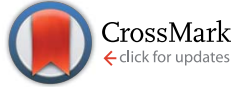

Cite this: J. Mater. Chem. C, 2014, 2 , 7614

Received 15th June 2014 Accepted 11th July 2014

DOI: $10.1039 / c 4 t c 01277 a$

www.rsc.org/MaterialsC

\section{A star-shaped $D-\pi-A$ small molecule based on a tris(2-methoxyphenyl)amine core for highly efficient solution-processed organic solar cells $\uparrow$}

\author{
Jie Min, ${ }^{\text {a }}$ Yuriy N. Luponosov, ${ }^{\text {b }}$ Alexander N. Solodukhin, ${ }^{\mathrm{b}}$ Nina Kausch-Busies, ${ }^{c}$ \\ Sergei A. Ponomarenko, ${ }^{\text {bd }}$ Tayebeh Ameri ${ }^{\mathrm{a}}$ and Christoph J. Brabec ${ }^{\text {ae }}$ \\ A new star-shaped $D-\pi-A$ small molecule, 2,2', $2^{\prime \prime}$-\{nitrilotris[(3-methoxy-4,1-phenylene)-2,2' -bithiene- \\ 5',5-diyleth-1-yl-1-ylidene]\}trimalononitrile $\mathrm{N}(\mathrm{Ph}(\mathrm{OMe})-2 \mathrm{~T}-\mathrm{DCN}-\mathrm{Me})_{3}$, with high efficiency potential for \\ photovoltaic applications was synthesized. Introducing a soluble tris(2-methoxyphenyl)amine (TPA-MeO) \\ core unit can significantly improve the solubility of star-shaped small molecules without negatively \\ impacting intramolecular conjugation and intermolecular solid state arrangements. Solution-processed \\ organic solar cells based on a blend of $\mathrm{N}(\mathrm{Ph}(\mathrm{OMe})-2 \mathrm{~T}-\mathrm{DCN}-\mathrm{Me})_{3}$ and $\mathrm{PC}_{70} \mathrm{BM}$ show an initially high \\ power conversion efficiency of over $4 \%$ under simulated AM 1.5 .
}

\section{Introduction}

The dynamic development in solution-processed small molecule organic solar cells (OSCs) has recently led to high power conversion efficiencies (PCEs) of $>8 \%$ approaching those of polymer-based devices with the most promising bulk heterojunction (BHJ) architecture..$^{1-3}$ Compared to their polymeric counterparts, structurally well-defined small molecules avoid the inherent batch-to-batch variations of physical properties and therefore provide higher reproducibility. ${ }^{4-6}$ The current research pursuits for small molecule-based OSCs target even higher efficiencies by designing and synthesizing new organic small molecules, such as star- or X-shaped molecules and ${ }^{7-10}$ one- or two-dimensional oligomers with $\mathrm{D}-\mathrm{A}-\mathrm{D}$ or $\mathrm{A}-\mathrm{D}-\mathrm{A}$ structures. ${ }^{3,11-16}$ In particular, the most promising organic small molecule donor materials for photovoltaic applications are normally built by connecting various electron donating (donor) and electron capturing (acceptor) moieties through a $\pi$-conjugating spacer $(\mathrm{D}-\pi-\mathrm{A}) .^{7-9,11-16}$ Such a $\mathrm{D}-\pi-\mathrm{A}$ structure can be

\footnotetext{
anstitute of Materials for Electronics and Energy Technology (I-MEET), Friedrich-Alexander-University Erlangen-Nuremberg, Martensstraße 7, 91058 Erlangen, Germany. E-mail: Min.Jie@ww.uni-erlangen.de

${ }^{b}$ Enikolopov Institute of Synthetic Polymeric Materials of the Russian Academy of Sciences, Profsoyuznaya st. 70, Moscow 117393, Russia

${ }^{c}$ Heraeus Precious Metals GmbH \& Co. KG, Conductive Polymers Division (Clevios), Chempark Leverkusen Build. B202, D-51368 Leverkusen, Germany

${ }^{d}$ Chemistry Department, Moscow State University, Leninskie Gory 1-3, Moscow 119991, Russia

${ }^{e}$ Bavarian Center for Applied Energy Research (ZAE Bayern), Haberstraße 2a, 91058 Erlangen, Germany

$\dagger$ Electronic supplementary information (ESI) available: TGA and DSC plots, $J-V$ curves of OSCs with various D : A ratios, and ${ }^{1} \mathrm{H}$ and ${ }^{13} \mathrm{C}$ NMR spectra of monomers. See DOI: 10.1039/c4tc01277a
}

used to lower the optical band gap to broaden molecular optical absorption and to assist the formation of favorable morphologies for high photovoltaic performance. ${ }^{17} \mathrm{~A}$ large number of $\mathrm{D}-\pi-\mathrm{A}$ small molecules have been extensively studied and exhibit considerable molecular photovoltaic properties. For instance, Li et al. and Chen et al. synthesized two two-dimensional small molecules, D2 and DR3TBDTT with an A- $\pi-\mathrm{D}-\pi-\mathrm{A}$ framework which show excellent photovoltaic performance with PCEs of up to $6.75 \%$ and $8.12 \%$, respectively. ${ }^{3,12}$ Bazan and his co-workers synthesized a promising linear molecule, DTS(FBTTh $\left.{ }_{2}\right)_{2}$ with a high PCE up to $7 \%,{ }^{18}$ and then introduced an optical spacer ( $\mathrm{ZnO}$ ) between the aluminum cathode and the photoactive layers to further improve the PCE. ${ }^{1 b}$ More recently, using a two-dimensional conjugated small molecule (SMPV1), the best PCE of OSCs reached $8 \%$ for single junction solar cells, and $10 \%$ for double-junction tandem OSCs,${ }^{19}$ endowing organic small molecules with a great application potential for the generation of low cost solar cells.

However, compared to $\pi$-conjugated polymers, the relatively short conjugated backbone of $\mathrm{D}-\pi-\mathrm{A}$ linear small molecules reduces the tendency for the formation of interpenetrating networks and mixed morphologies when blended with fullerene derivatives. ${ }^{20}$ The limited conjugation length also makes charge transport in these materials primarily intermolecular with a negligible intramolecular component, which increases charge recombination in OSCs. ${ }^{8 b}$ In addition, the dependence of photovoltaic performance on the spin-coated processing system further limits the applications of these materials in roll-to-roll processed flexible photovoltaic devices. Overcoming these obstacles requires enhancing intramolecular $\pi-\pi$ stacking interactions, facilitating charge transport and forming a process-insensitive morphology in OSCs, as well as further increasing the PCE. A promising approach is to incorporate 
star-shaped conjugated structures into $\mathrm{D}-\pi-\mathrm{A}$ conjugated systems., ${ }^{7,8,20}$ These star-shaped molecules, which enhance intramolecular $\pi-\pi$ interactions and extend the conjugated surface of small molecules, can effectively be utilized in OSCs using the doctor-bladed process. ${ }^{7,8}$ These results drive us to pay more attention to the high performance star-shaped small molecules for OSCs.

In recent years, star-shaped molecules have been developed as an interesting class of semiconducting materials because of their good solubility and high hole mobility., ${ }^{5,81,22}$ However, analyzing the performance of one- or two-dimensional small molecules for OSCs, star- or X-shaped molecules encountered a huge bottleneck due to the relatively low fill factor (FF) and modest short circuit current $\left(J_{\mathrm{sc}}\right)$. Nevertheless, several interesting insights into three-dimensional star-shaped molecules were achieved. Tu et al. reported spiro-fluorene based starshaped molecules, SF8TBT, which showed a high PCE of $4.82 \%$, with a FF of $56 \% .^{23}$ Moreover, a comparable PCE was also achieved for the triphenylamine (TPA) based molecule N(Ph-2TDCN-Me) $)_{3}$ (ref. $8 a$ ) after optimizing the alkyl chain position and length and thus reducing the steric hindrance and torsional interactions between $\mathrm{D} / \mathrm{A}$ units and bithiophene $\pi$-bridges. However, N(Ph-2T-DCN-Me $)_{3}$ was found to be significantly less soluble at room temperature, thereby limiting the selection of printing methods for OSC processing. In addition, and due to the importance of the molecular design of the alkyl side chain position and length with respect to solubility and film morphology, ${ }^{7,8}$ in this contribution, we introduce a novel tris(2methoxyphenyl)amine (TPA-MeO) donor unit as a core. We synthesized a new star-shaped small molecule of $\mathbf{N}(\mathbf{P h}(\mathbf{O M e})-$

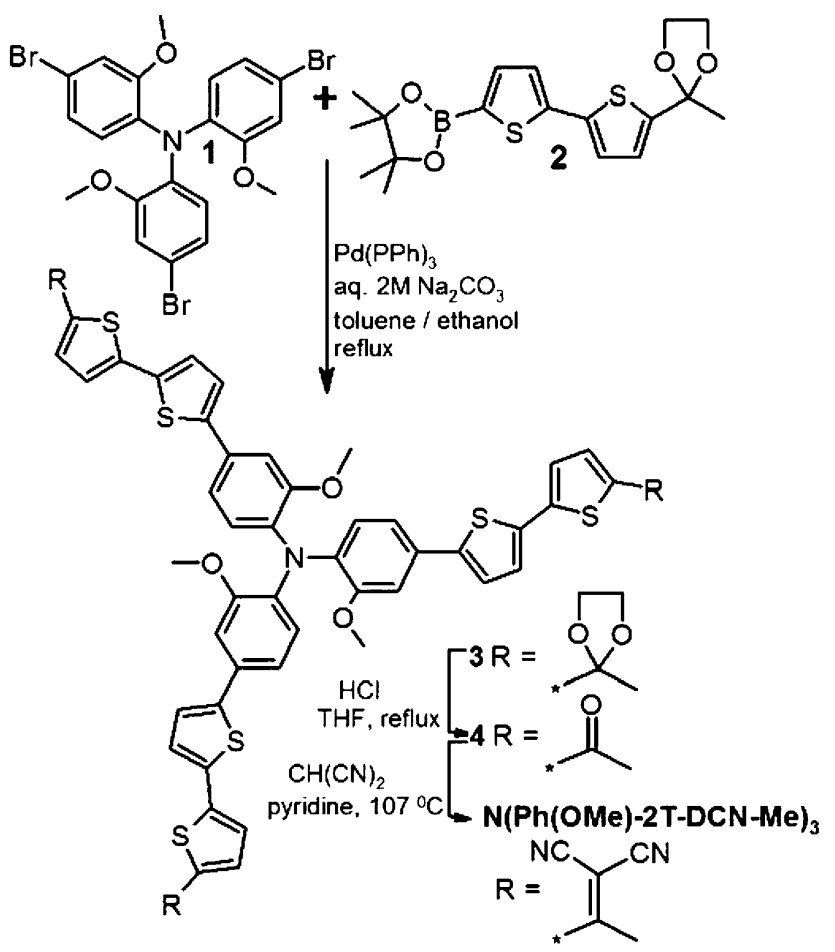

Scheme 1 Synthesis of $\mathrm{N}(\mathrm{Ph}(\mathrm{OMe})-2 \mathrm{~T}-\mathrm{DCN}-\mathrm{Me})_{3}$.
2T-DCN-Me) ${ }_{3}$ with electron-withdrawing dicyanovinyl (DCN) end groups and bithiophene as $\pi$-bridges (Scheme 1). Since the introduction of a methoxy side chain in N(Ph(OMe)-2T-DCN$\mathbf{M e})_{3}$ obviously does not enhance steric hindrance or cause intramolecular torsional interactions between bithiophene bridges and end groups, this strategy allows designing superior solution processability as compared to that of N(Ph-2T-DCN$\mathrm{Me})_{3}$, in combination with good thermal stability and high charge carrier mobilities in blends with 6,6-phenyl-C71-butyric acid methyl ester $\left(\mathrm{PC}_{70} \mathrm{BM}\right)$. Solution-processed bulk heterojunction (BHJ) OSCs based on N(Ph(OMe)-2T-DCNMe $)_{3}: \mathrm{PC}_{70} \mathrm{BM}(1: 2, \mathrm{wt} \%)$ exhibit a high PCE of $4.38 \%$ with a $V_{\mathrm{oc}}$ of $0.88 \mathrm{~V}, \mathrm{a} J_{\mathrm{sc}}$ of $9.15 \mathrm{~mA} \mathrm{~cm} \mathrm{~cm}^{-2}$, and an $\mathrm{FF}$ of $54.4 \%$, under the illumination of AM1.5G, $100 \mathrm{~mW} \mathrm{~cm}^{-2}$.

\section{Results and discussion}

\section{Synthesis and characterization of $\mathrm{N}(\mathrm{Ph}(\mathrm{OMe})-2 \mathrm{~T}-\mathrm{DCN}-\mathrm{Me})_{3}$}

Preparation of this molecule was based on a previously developed synthetic approach for triphenylamine-based analogues ${ }^{7,8}$ and includes the synthesis of the star-shaped molecule with protected carbonyl groups (3) via Suzuki cross-coupling of $\mathbf{1}$ and 2 followed by the deprotection reaction and the final Knövenagel condensation of triketones (4) with malononitrile under microwave heating (Scheme 1). The thermal properties were investigated by thermogravimetric analysis (TGA) and differential scanning calorimetry (DSC). Fig. S1 (see ESI $\dagger$ ) shows the results of TGA of the studied compound in air and nitrogen flow correspondingly. TGA reveals an onset decomposition temperature (at $5 \%$ weight-loss $\left(T_{\mathrm{d}}\right)$ ) in air and under an inert atmosphere at approx. $402{ }^{\circ} \mathrm{C}$ (Fig. $\left.\mathrm{S} 1 \dagger\right)$, which is adequately suitable for OSC fabrication and evaluation. The first DSC trace of the novel molecule shows a melting peak at $248{ }^{\circ} \mathrm{C}$ with $\Delta H=53.48$ $\mathrm{J} \mathrm{g}^{-1}$, which underlines the crystalline nature of this material when processed from solution. However, subsequent cooling and second heating (Fig. S2 $\dagger$ ) show the otherwise amorphous nature of $\mathbf{N}(\mathbf{P h}(\mathbf{O M e})-2 \mathrm{~T}-\mathbf{D C N}-\mathbf{M e})_{3}$ with the glass transition temperature at approx. $130{ }^{\circ} \mathrm{C}$, which is $22{ }^{\circ} \mathrm{C}$ less as compared to its analog without methoxy groups $\mathrm{N}(\mathrm{Ph}-2 \mathrm{~T}-\mathrm{DCN}-\mathrm{Me})_{3} \cdot{ }^{8 a, b}$ The solubility of this compound was determined in $o$-dichlorobenzene (ODCB) at room temperature by a reported method. ${ }^{8 b}$ Due to the solubilizing methoxy-substituents, N(Ph(OMe)-2TDCN-Me) ${ }_{3}$ possesses good room temperature solubility (14 $\mathrm{mg}$ $\left.\mathrm{mL}^{-1}\right)$ in ODCB, which is almost 5 times higher than that of $\mathrm{N}(\mathrm{Ph}-2 \mathrm{~T}-\mathrm{DCN}-\mathrm{Me})_{3}\left(<3 \mathrm{mg} \mathrm{mL}{ }^{-1}\right){ }^{8 a}$

\section{Photophysical and electrochemical properties}

Fig. 1a shows the UV-vis absorption spectra of N(Ph(OMe)-2TDCN-Me $)_{3}$ in ODCB solution and a thin solid film. In solution, the absorption peak at around $375 \mathrm{~nm}$ corresponds to the $\pi-\pi^{*}$ transition of the conjugated backbone, whereas the lower energy absorption band peaking at $513 \mathrm{~nm}$ is ascribed to the intermolecular charge transfer (ICT) transition. ${ }^{7,8 a}$ In comparison to their absorption in solution, the molecular absorption bands in film were red-shifted, extending the absorption edge from $604 \mathrm{~nm}$ in solution to $656 \mathrm{~nm}$ in the solid state, 
(a)

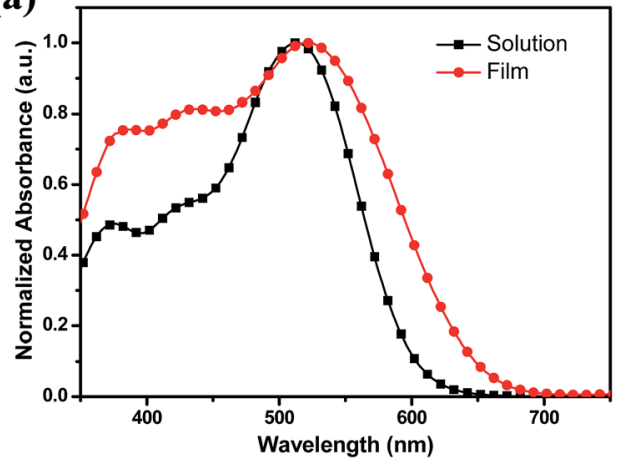

(b)

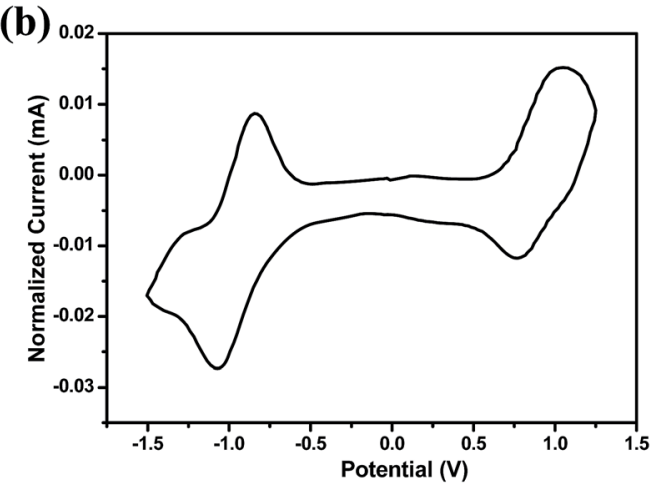

Fig. 1 (a) Absorption spectra of $\mathrm{N}(\mathrm{Ph}(\mathrm{OMe})-2 \mathrm{~T}-\mathrm{DCN}-\mathrm{Me})_{3}$ in ODCB and a thin film. (b) Cyclic voltammogram (1-st peaks, potentials vs. SCE) of the molecule measured in the ODCB-acetonitrile $(4: 1)$ mixture of solvents using $0.1 \mathrm{M} \mathrm{Bu}_{4} \mathrm{NPF}_{6}$ as a supporting electrolyte.

corresponding to an optical band gap $\left(E_{\mathrm{g}}\right)$ of $1.89 \mathrm{eV}$. The absorption peak of the thin film $(523 \mathrm{~nm})$ is bathochromically shifted by $10 \mathrm{~nm}$ relative to that in the solution $(513 \mathrm{~nm})$.

The electrochemical properties of $\mathbf{N}(\mathbf{P h}(\mathbf{O M e})-2 \mathrm{~T}-\mathbf{D C V}-\mathbf{M e})_{3}$ were investigated using cyclic voltammetry (CVA) (Fig. 1b). The measurements were carried out in the 1,2-dichlorobenzeneacetonitrile (4:1) mixture of solvents using $0.1 \mathrm{MBu}_{4} \mathrm{NPF}_{6}$ as a supporting electrolyte. The onset of the reduction potential ( $\left.\varphi_{\text {red }}\right)$ is $-0.95 \mathrm{~V} v s$. SCE, while the onset of the oxidation potential $\left(\varphi_{\mathrm{ox}}\right)$ is $0.90 \mathrm{~V}$ vs. SCE. The lowest unoccupied molecular orbital (LUMO) and the highest occupied molecular orbital (HOMO) energy levels were correspondingly calculated to be -3.45 and $-5.30 \mathrm{eV}$, according to LUMO $=-e\left(\varphi_{\text {red }}+4.40\right)$ $(\mathrm{eV})$ and HOMO $=-e\left(\varphi_{\mathrm{ox}}+4.40\right)(\mathrm{eV}) .{ }^{24} \mathrm{In}$ comparison to the HOMO level of N(Ph-2T-DCN-Me $)_{3}(-5.32 \mathrm{eV}),{ }^{8 a} \mathbf{N}(\mathbf{P h}(\mathrm{OMe})-2 \mathrm{~T}-$ DCV-Me $)_{3}$ showed a higher HOMO energy level, which should result in lower $V_{\mathrm{oc}}$ because the $V_{\mathrm{oc}}$ is usually proportional to the difference between the LUMO level of the acceptor and the HOMO level of the donor. ${ }^{25}$

\section{Photovoltaic properties}

The photovoltaic properties of $\mathbf{N}(\mathbf{P h}(\mathbf{O M e})-2 \mathrm{~T}-\mathrm{DCN}-\mathbf{M e})_{3}$ were preliminarily investigated by fabricating solution-processed $\mathrm{BHJ}$ devices in the conventional structure glass/ITO/
PEDOT:PSS/N(Ph(OMe)-2T-DCN-Me) $)_{3}: \mathrm{PC}_{70} \mathrm{BM} /$ various cathodes. The detailed device fabrication process is described in the Experimental section. To optimize the device condition, devices with different donor-acceptor weight ratios were examined, as shown in Fig. S3 and Table S1. $\uparrow$ All the devices yield relatively high $V_{\text {oc }}(0.88-0.90 \mathrm{~V})$ which are consistent with the deeper lowlying HOMO and are relatively insensitive to the donor: acceptor (D:A) blend ratio. Even though the weight ratios of the active layer had a huge difference from $1: 1$ to $1: 3$, $\mathbf{N}\left(\mathbf{P h}(\mathbf{O M e})_{3} \text {-2T-DCV-Me }\right)_{3}: \mathrm{PC}_{70} \mathrm{BM}$ based devices exhibited stable PCE values over 3\%, as shown in Table S1. $\dagger$ It was presented that the OSC with the D : A weight ratio of $1: 2$ showed the best PCE of $3.92 \%$ with a $V_{\mathrm{oc}}$ of $0.88 \mathrm{~V}$, a $J_{\mathrm{sc}}$ of $8.45 \mathrm{~mA} \mathrm{~cm} \mathrm{~cm}^{-2}$ and a $\mathrm{FF}$ of $52.7 \%$, under the illumination of $\mathrm{AM} 1.5 \mathrm{G}$ at 100 $\mathrm{mW} \mathrm{cm}{ }^{-2}$. Compared to the performance of the N(Ph-2T-DCN$\mathrm{Me})_{3}: \mathrm{PC}_{70} \mathrm{BM}$ based device, ${ }^{8 a}$ the device using the $\mathbf{N}\left(\mathbf{P h}(\mathbf{O M e})_{\mathbf{3}^{-}}\right.$ 2T-DCV-Me $)_{3}: \mathrm{PC}_{70} \mathrm{BM}$ blend showed lower $V_{\mathrm{oc}}(0.98 \mathrm{~V} v$ s. $0.88 \mathrm{~V})$, which was consistent with the higher HOMO level due to electron donating methoxy substituents. However, $\mathbf{N}\left(\mathbf{P h}(\mathbf{O M e})_{3}-2 \mathrm{~T}-\right.$ DCV-Me $)_{3}$ is more suitable for solution processed electronic devices. Since the photovoltaic performance frequently depends on the choice of the cathode, ${ }^{1,8 c}$ we further studied the impact of various cathode materials including $\mathrm{Al}, \mathrm{Ca} / \mathrm{Al}$ and $\mathrm{ZnO} / \mathrm{Al}$, on the photovoltaic performance. Fig. 2 shows the current density-
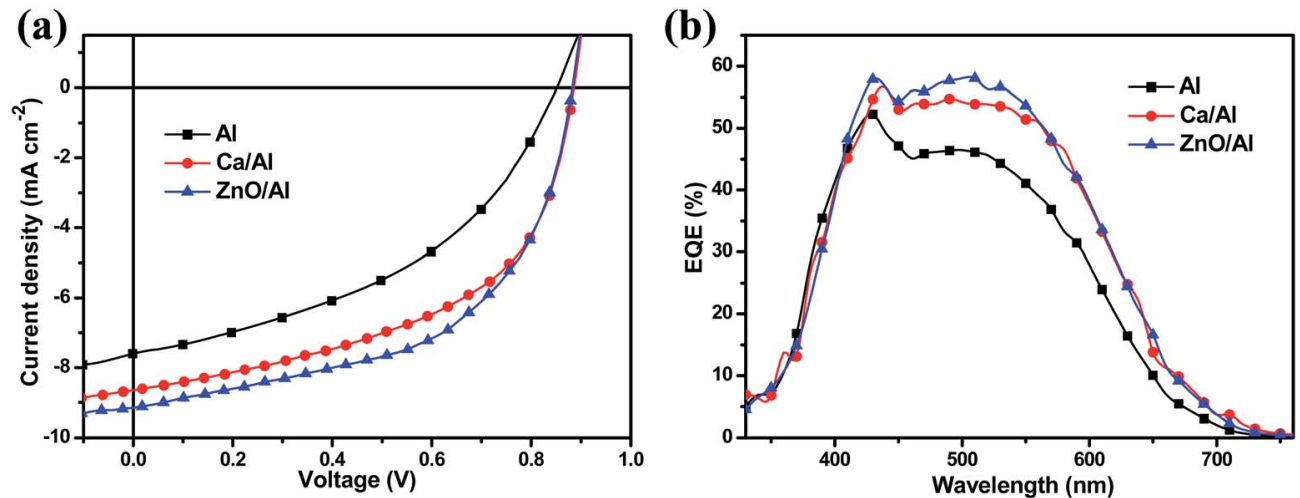

Fig. 2 (a) The $J-V$ curves of the $\mathrm{N}(\mathrm{Ph}(\mathrm{OMe})-2 \mathrm{~T}-\mathrm{DCN}-\mathrm{Me})_{3}: \mathrm{PC}_{70} \mathrm{BM}$ OSCs with various cathodes under the illumination of $\mathrm{AM} 1.5 \mathrm{G}$ at $100 \mathrm{~mW}$ $\mathrm{cm}^{-2}$ and (b) the EQE curves of the devices. 
Table 1 The photovoltaic performance of the OSCs based on $\mathrm{N}(\mathrm{Ph}(\mathrm{OMe})-2 \mathrm{~T}-\mathrm{DCV}-\mathrm{Me})_{3}: \mathrm{PC}_{70} \mathrm{BM}$ blends, under the illumination of AM $1.5 \mathrm{G}$ at $100 \mathrm{~mW} \mathrm{~cm}^{-2}$

\begin{tabular}{lllll}
\hline Cathodes & $V_{\text {oc }}[\mathrm{V}]$ & $J_{\text {sc }}\left[\mathrm{mA} \mathrm{cm}^{-2}\right]$ & $\mathrm{FF}[\%]$ & $\mathrm{PCE}_{\max }\left(\mathrm{PCE}_{\text {ave }}{ }^{a}\right)[\%]$ \\
\hline $\mathrm{Al}$ & 0.85 & 7.60 & 43.6 & $2.82(2.73)$ \\
$\mathrm{Ca} / \mathrm{Al}$ & 0.88 & 8.45 & 52.7 & $3.92(3.80)$ \\
$\mathrm{ZnO} / \mathrm{Al}$ & 0.88 & 9.15 & 54.4 & $4.38(4.25)$
\end{tabular}

${ }^{a}$ The average PCE is obtained from six cells.

voltage $(J-V)$ curves of the OSC based on N(Ph(OMe)-2T-DCN$\mathbf{M e})_{3}: \mathrm{PC}_{70} \mathrm{BM}(1: 2$, wt $\%)$ with various cathodes as well as the external quantum efficiency (EQE) plots. Compared to the devices with $\mathrm{Ca} / \mathrm{Al}$ and $\mathrm{ZnO} / \mathrm{Al}$ cathodes, the device with the $\mathrm{Al}$ cathode showed a low $V_{\text {oc }}(0.88 \mathrm{~V} v s .0 .85 \mathrm{~V})$, which is consistent with the unsuitable contact formation between the active layer and the $\mathrm{Al}$ cathode. In contrast, the $\mathrm{Ca} / \mathrm{Al}$ device exhibits higher photovoltaic parameters due to enhanced charge extraction. The device was further improved by inserting a thin $\mathrm{ZnO}$ layer ( $25 \mathrm{~nm}$ ) between the active layer and the Al cathode. Compared to the performance of the Al-only device, the PCE of the device with the $\mathrm{ZnO}$ interfacial layer increases from $2.82 \%$ to $4.38 \%$, mainly due a higher $J_{\mathrm{sc}}$ of $9.15 \mathrm{~mA} \mathrm{~cm} \mathrm{~cm}^{-2}$ and a better $\mathrm{FF}$ of $54.4 \%$, as shown in Fig. 2 and Table 1 . The EQE curves of the devices symbiotically covered a broad wavelength range of 300$670 \mathrm{~nm}$ suggesting that at the analysed film thickness both, $\mathbf{N}(\mathbf{P h}(\mathrm{OMe})-2 \mathrm{~T}-\mathrm{DCN}-\mathrm{Me})_{3}$ and $\mathrm{PC}_{70} \mathrm{BM}$ contribute to the photocurrent. In addition, the EQE curves are well consistent with the $J_{\mathrm{sc}}$ values measured under simulated AM 1.5.

\section{Film morphology and charge transport}

Nanoscale phase separation in the morphology of the active layer is required for high performance OSCs, which enables a large interfacial area for exciton dissociation and a continuous percolating path for hole and electron transport to the corresponding electrodes. ${ }^{26}$ Here, the atomic force microscopy (AFM) images of the active layer were examined with and without a top
ZnO layer, as shown in Fig. 3. The AFM phase image of the blend film of $\mathbf{N}(\mathbf{P h}(\mathbf{O M e})-2 \mathrm{~T}-\mathrm{DCN}-\mathrm{Me})_{3}: \mathrm{PC}_{70} \mathrm{BM}(1: 2, \mathrm{wt} \%)$, exhibited a smooth surface (root mean square (RMS) roughness of $0.35 \mathrm{~nm}$ ) with good interconnected regions and domains, which is beneficial to exciton dissociation and charge carrier transport. ${ }^{26}$ Fig. 3b shows that the $\mathrm{ZnO}$ nanoparticles were evenly deposited on the surface of the active layer. Deposition of $\mathrm{ZnO}$ nanoparticles on the active layer under the experimental conditions described here also resulted in increased roughness from $0.35 \mathrm{~nm}$ to $5.76 \mathrm{~nm}$.

The hole and electron mobility of $\mathbf{N}\left(\mathbf{P h}(\mathbf{O M e})_{3}-2 \text { T-DCV-Me }\right)_{3}$ were determined via the space charge limited current (SCLC) method with the device structure glass/ITO/PEDOT:PSS/active layer/ $\mathrm{MoO}_{3} / \mathrm{Ag}(100 \mathrm{~nm})$ and ITO/aluminum doped $\mathrm{ZnO}(\mathrm{AZO}) /$ active layer/Ca/Ag, respectively. We calibrated the hole and electron mobility by fitting the current-voltage curves over six diodes, ${ }^{7}$ as shown in Fig. 4. The hole and electron mobility obtained for the $\mathbf{N}\left(\mathbf{P h}(\mathbf{O M e})_{3}-2 T-D C V-M e\right)_{3}: \mathrm{PC}_{70} \mathrm{BM}(1: 2, \mathrm{wt} \%)$ blend films are $5.19 \times 10^{-5}$ and $1.25 \times 10^{-3} \mathrm{~cm}^{2} \mathrm{~V}^{-1} \mathrm{~s}^{-1}$, respectively.

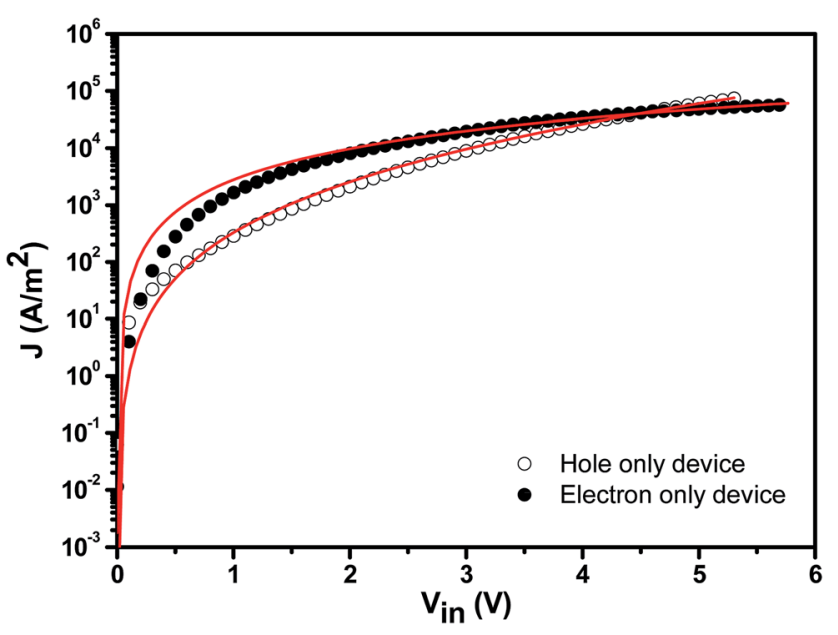

Fig. 4 Hole only mobility and electron only mobility of $\mathrm{N}(\mathrm{Ph}(\mathrm{OMe})-$ $2 \mathrm{~T}-\mathrm{DCN}-\mathrm{Me})_{3}: \mathrm{PC}_{70} \mathrm{BM}(1: 2, \mathrm{wt} \%)$ blended films.
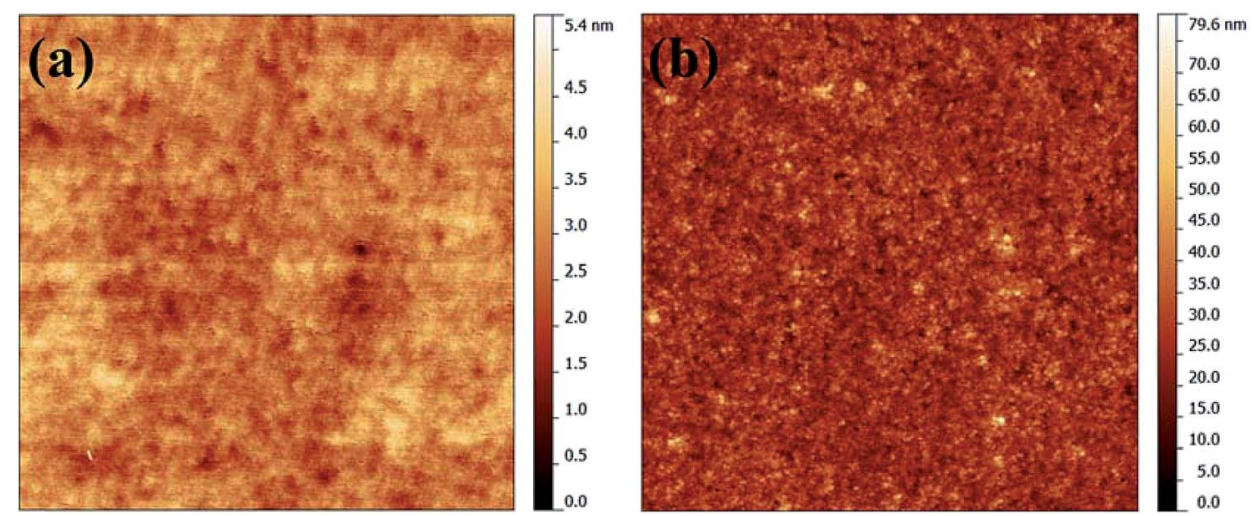

Fig. 3 Tapping mode AFM surface scans $\left(5 \times 5 \mu \mathrm{m}^{2}\right)$ of the $\mathrm{N}(\mathrm{Ph}(\mathrm{OMe})-2 \mathrm{~T}-\mathrm{DCN}-\mathrm{Me})_{3}: \mathrm{PC}_{70} \mathrm{BM}(1: 2$, wt\%) blends (a) without and (b) with the $\mathrm{ZnO}$ layer. The film surfaces show the root-mean-square (RMS) roughness of $0.35 \mathrm{~nm}$ for (a) and $5.76 \mathrm{~nm}$ for (b). 


\section{Conclusions}

In conclusion, a new star-shaped small molecule, $\mathbf{N}(\mathbf{P h}(\mathbf{O M e})-$ 2T-DCN-Me $)_{3}$, with a D- $\pi$-A framework was synthesized. It has excellent solution processing characteristics due to the more soluble TPA-MeO core unit. The BHJ OSCs based on N(Ph(OMe)2T-DCN-Me $)_{3}: \mathrm{PC}_{70} \mathrm{BM}(1: 2, \mathrm{wt} \%)$ as an active layer and with a $\mathrm{ZnO} / \mathrm{Al}$ as cathode show an initially high PCE of $4.38 \%$ without any special treatment needed. This preliminary work demonstrates that the TPA-MeO donor unit offers a good strategy to improve the solubility of star-shaped small molecule donor materials without negatively impacting intramolecular conjugation and intermolecular solid state arrangements. In addition, the optimized performance of the device using the $\mathrm{ZnO}$ layer suggests that this device structure is especially useful in roll-to-roll processing flexible and large-area electronics.

\section{Experimental section}

\section{General}

GPC analysis was performed by using a Shimadzu LC10A ${ }^{\mathrm{VP}}$ series chromatograph (Japan) equipped with an RID-10A ${ }^{\mathrm{VP}}$ refractometer and an SPD-M10A ${ }^{\mathrm{VP}}$ diode matrix as detectors and a Phenomenex column (USA) with a size of $7.8 \times 300 \mathrm{~mm}^{2}$ filled with the Phenogel sorbent with a pour size of $500 \AA$; THF was used as the eluent. For thin layer chromatography, "Sorbfil" (Russia) plates were used. In the case of column chromatography, silica gel 60 ("Merck") was taken.

${ }^{1} \mathrm{H}$ NMR spectra were recorded on a "Bruker WP-250 SY" spectrometer, working at a frequency of $250.13 \mathrm{MHz}$ and utilising a $\mathrm{CDCl}_{3}$ signal $(7.25 \mathrm{ppm})$ as the internal standard. ${ }^{13} \mathrm{C}$ NMR spectra were recorded on a Bruker DRX500 at a frequency of $125 \mathrm{MHz}$. In the case of ${ }^{1} \mathrm{H}$ NMR spectroscopy, the compounds to be analysed were taken in the form of $1 \%$ solutions in $\mathrm{CDCl}_{3}$. In the case of ${ }^{13} \mathrm{C}$ NMR spectroscopy, the compounds to be analysed were taken in the form of $5 \%$ solutions in $\mathrm{CDCl}_{3}$. The spectra were then processed on the computer using the ACD Labs software.

Mass-spectra (MALDI) were recorded on the Autoflex II Bruker (resolution FWHM 18000), equipped with a nitrogen laser (work wavelength $337 \mathrm{~nm}$ and time-of-flight mass-detector working in reflections mode). The accelerating voltage was $20 \mathrm{kV}$. The samples were applied to a polished stainless steel substrate. The spectrum was recorded in the positive ion mode. The resulting spectrum was the sum of 300 spectra obtained at different points of the sample. 2,5-Dihydroxybenzoic acid (DHB) (Acros, 99\%) and $\alpha$-cyano-4-hydroxycinnamic acid (HCCA) (Acros, 99\%) were used as matrices.

Elemental analysis of C, H, N elements was carried out using a CHN automatic analyzer CE 1106 (Italy). The settling titration using $\mathrm{BaCl}_{2}$ was applied to analyze sulphur. Experimental error is $0.30-0.50 \%$.

The Knövenagel condensation was carried out in the microwave "Discovery", (CEM Corporation, USA), using a standard method with the open vessel option, 50 watts. Thermogravimetric analysis was carried out in dynamic mode in a 30/ $900{ }^{\circ} \mathrm{C}$ interval using a Mettler Toledo TG50 system equipped with an M3 microbalance allowing measuring the weight of samples in the $0-150 \mathrm{mg}$ range with $1 \mu \mathrm{g}$ precision. The heating/ cooling rate was chosen to be $10{ }^{\circ} \mathrm{C} \mathrm{min}{ }^{-1}$. The compound was studied twice: in air and in a nitrogen flow of $200 \mathrm{~mL} \mathrm{~min}^{-1}$.

DSC scans were obtained with a Mettler Toledo DSC30 system with a $20{ }^{\circ} \mathrm{C} \mathrm{min}^{-1}$ heating/cooling rate in the temperature range of $+20-250{ }^{\circ} \mathrm{C}$ for the compound. A nitrogen flow of $50 \mathrm{~mL} \mathrm{~min}^{-1}$ was used.

Absorption profiles were recorded with a Perkin Elmer Lambda-35 absorption spectrometer from 350 to 1100. Electrochemical properties were studied by cyclic voltammetry (CVA). The measurements were carried out in the 1,2-dichlorobenzene-acetonitrile (4:1) mixture of solvents using $0.1 \mathrm{M}$ $\mathrm{Bu}_{4} \mathrm{NPF}_{6}$ as the supporting electrolyte. The glassy carbon electrode was used as a working electrode. Potentials were measured relative to a saturated calomel electrode.

\section{Materials}

Tetrakis(triphenylphosphine)palladium $(0) \mathrm{Pd}\left(\mathrm{PPh}_{3}\right)_{4}$ and malononitrile were obtained from Sigma-Aldrich Co. and used without further purification. Pyridine was dried and purified according to the known techniques and then used as a solvent. Tris(4-bromo-2-methoxyphenyl)amine was obtained as described in ref. 27. 2-[5'-(2-methyl-1,3-dioxolan-2-yl)-2,2' bithien-5-yl]-4,4,5,5-tetramethyl-1,3,2-dioxaborolane (2) was obtained as described previously. ${ }^{8 a}$

\section{Synthesis}

Tris\{2-methoxy-4-[5'-(2-methyl-1,3-dioxolan-2-yl)-2,2'-bithien5-yl]phenyl \}amine (3). In an inert atmosphere, degassed solutions of tris(4-bromo-2-methoxy-phenyl)amine (1) (2.24 g, 3.9 $\mathrm{mmol}$ ) and 2-[5'-(2-methyl-1,3-dioxolan-2-yl)-2,2'-bithien-5-yl]4,4,5,5-tetramethyl-1,3,2-dioxaborolane (2) (5.33 g, $14.1 \mathrm{mmol}$ ) in a toluene-ethanol mixture $(70 / 7 \mathrm{~mL})$ and $2 \mathrm{M}$ solution of aq. $\mathrm{Na}_{2} \mathrm{CO}_{3}(21.1 \mathrm{~mL})$ were added to $\mathrm{Pd}\left(\mathrm{PPh}_{3}\right)_{4}(489 \mathrm{mg}, 0.4 \mathrm{mmol})$. The reaction mixture was stirred under reflux for $10 \mathrm{~h}$, and then it was cooled to room temperature and poured into $150 \mathrm{~mL}$ of water and $150 \mathrm{~mL}$ of toluene. The organic phase was separated, washed with water, dried over sodium sulfate and filtered. The solvent was evaporated in vacuum and the residue was dried at 1 Torr. The product was purified by column chromatography on silica gel (eluent toluene) to give pure compound 4 (3.6 g, 84\%) as a yellow solid. ${ }^{1} \mathrm{H}$ NMR $\left(250 \mathrm{MHz}, \mathrm{CDCl}_{3}\right): \delta[\mathrm{ppm}] 1.79(\mathrm{~s}$, 9H), 3.66 (s, 9H), 3.92-4.15 (overlapping peaks, 12H), 6.83 (d, $3 \mathrm{H}, J=8.7 \mathrm{~Hz}), 6.93(\mathrm{~d}, 3 \mathrm{H}, J=3.7 \mathrm{~Hz}), 7.01(\mathrm{~d}, 3 \mathrm{H}, J=3.7 \mathrm{~Hz})$, 7.04-7.12 (overlapping peaks, 9H), 7.15 (d, 3H, $J=3.7 \mathrm{~Hz}) .{ }^{13} \mathrm{C}$ NMR (125 MHz, $\mathrm{CDCl}_{3}$ ): $\delta[\mathrm{ppm}]$ 27.51, 55.96, 65.05, 107.11, 109.82 , 118.17, 123.04, 123.1, 124.51, 124.76, 124.91, 130.1, 135.91, 136.68, 137.19, 143.43, 146.14, 153.14. Calcd (\%) for $\mathrm{C}_{57} \mathrm{H}_{51} \mathrm{NO}_{9} \mathrm{~S}_{6}: \mathrm{C}, 63.02 ; \mathrm{H}, 4.73 ; \mathrm{N}, 1.29 ; \mathrm{S}, 17.71$. Found: C, 62.88; H, 4.75; N, 1.22; S, 17.47. MALDI-MS: found $\mathrm{m} / \mathrm{z} 1084.68$; calculated for $[\mathrm{M}]^{+} 1085.18$.

$1,1^{\prime}, 1^{\prime \prime}$-\{Nitrilotris[(3-methoxy-4,1-phenylene)-2,2' -bithiene$5^{\prime}$,5-diyl]\}triethanone (4). $1 \mathrm{M} \mathrm{HCl}(5.52 \mathrm{~mL})$ was added to a solution of compound $3(3.00 \mathrm{~g}, 2.8 \mathrm{mmol})$ in THF $(20 \mathrm{~mL})$ and then the reaction mixture was stirred for 3 hours at reflux at 
boiling temperature. During the reaction the product was gradually formed as an orange precipitate. After completion of the reaction the organic phase was separated using diethyl ether, washed with water and filtered off to give pure compound $4(2.27 \mathrm{~g}, 86 \%)$ as orange crystals. ${ }^{1} \mathrm{H}$ NMR $\left(250 \mathrm{MHz}, \mathrm{CDCl}_{3}\right): \delta$ [ppm] $2.54(\mathrm{~s}, 9 \mathrm{H}), 3.67(\mathrm{~s}, 9 \mathrm{H}), 6.85(\mathrm{~d}, 3 \mathrm{H}, J=9.1 \mathrm{~Hz}), 7.02-$ 7.14 (overlapping peaks, 6H), $7.16(\mathrm{~d}, 3 \mathrm{H}, J=4.3 \mathrm{~Hz}), 7.20(\mathrm{~d}$, $3 \mathrm{H}, J=4.3 \mathrm{~Hz}), 7.27(\mathrm{~d}, 3 \mathrm{H}, J=3.7 \mathrm{~Hz}), 7.58(\mathrm{~d}, 3 \mathrm{H}, J=4.3 \mathrm{~Hz})$. ${ }^{13} \mathrm{C}$ NMR (125 $\left.\mathrm{MHz}, \mathrm{CDCl}_{3}\right): \delta[\mathrm{ppm}] 26.65,56.13,110.17$, 118.59, 123.59, 123.88, 124.99, 126.75, 129.91, 133.55, 134.88, 137.12, 142.28, 145.81, 146.03, 153.33, 190.38. Calcd (\%) for $\mathrm{C}_{51} \mathrm{H}_{39} \mathrm{NO}_{6} \mathrm{~S}_{6}: \mathrm{C}, 64.19 ; \mathrm{H}, 4.12 ; \mathrm{N}, 1.47 ; \mathrm{S}, 20.16$. Found: C, 64.27; H, 4.26; N, 1.46; S, 20.21. MALDI-MS: found $\mathrm{m} / \mathrm{z}$ 952.66; calculated for $[\mathrm{M}]^{+}$953.11.

$2,2^{\prime}, 2^{\prime \prime}-\{$ Nitrilotris [(3-methoxy-4,1-phenylene)-2,2'-bithiene$5^{\prime}$, 5-diyleth-1-yl-1-ylidene] trimalononitrile (N(Ph(OMe)-2TDCN-Me $)_{3}$ ). Compound 4 (2.42 g, $\left.2.5 \mathrm{mmol}\right)$, malononitrile $(1.17 \mathrm{~g}, 17.8 \mathrm{mmol})$ and dry pyridine $(50 \mathrm{~mL})$ were placed in a reaction vessel and stirred under an argon atmosphere for 8 hours at $107^{\circ} \mathrm{C}$ using the microwave heating. After completion of the reaction the pyridine was evaporated in vacuum and the residue was dried at 1 Torr. This crude product was purified by column chromatography on silica gel (eluent dichloromethane). Further purification included precipitation of the product from its THF solution with toluene and hexane to give the pure product as a black solid (1.82 g, 67\%). ${ }^{1} \mathrm{H}$ NMR (250 $\left.\mathrm{MHz}, \mathrm{CDCl}_{3}\right): \delta[\mathrm{ppm}] 2.67(9 \mathrm{H}, \mathrm{s}), 3.68(9 \mathrm{H}, \mathrm{s}), 6.87$ (d, 3H, $J=$ $7.9 \mathrm{~Hz}$ ), 7.07-7.15 (overlapping peaks, 6H), $7.26(\mathrm{~d}, 3 \mathrm{H}, J=4.3$ $\mathrm{Hz}), 7.35$ (d, 3H, $J=4.3 \mathrm{~Hz}), 7.94$ (d, 3H, $J=4.3 \mathrm{~Hz}) .{ }^{13} \mathrm{C} \mathrm{NMR}$ $\left(125 \mathrm{MHz}, \mathrm{CDCl}_{3}\right): \delta[\mathrm{ppm}] 23.18,56.15,110.17,114.14,114.69$, 118.68, 123.92, 124.66, 125.06, 127.82, 129.69, 133.68, 135.56, $135.78,137.28,147.17,153.37,161.12$. Calcd (\%) for $\mathrm{C}_{60} \mathrm{H}_{39} \mathrm{~N}_{7} \mathrm{O}_{3} \mathrm{~S}_{6}: \mathrm{C}, 65.61 ; \mathrm{H}, 3.58 ; \mathrm{N}, 8.93 ; \mathrm{S}, 17.51$. Found: $\mathrm{C}$, 65.82; H, 3.72; N, 8.71; S, 17.29. MALDI-MS: found $\mathrm{m} / \mathrm{z} 1096.65$; calculated for $[\mathrm{M}]^{+} 1097.14$.

\section{Device fabrication}

Photovoltaic devices were fabricated by doctor-blading on indium-tin oxide (ITO)-covered glass substrates (from Osram). These substrates were cleaned in toluene, water, acetone, and isopropyl alcohol. After drying, the substrates were bladed with 40 nm PEDOT:PSS (HC Starck, PEDOT PH-4083). Photovoltaic layers, consisting of $\mathbf{N}(\mathbf{P h}(\mathbf{O M e})-2 \mathrm{~T}-\mathbf{D C N}-\mathbf{M e})_{3}$ and $\mathrm{PC}_{70} \mathrm{BM}$ in different weight ratios, were dissolved at the concentration of $1 \%$ (10 $\mathrm{mg} \mathrm{mL}^{-1}$ ) in dichlorobenzene (ODCB) and bladed on top of the PEDOT:PSS layer. Finally, a calcium/aluminum top electrode of 15/80 $\mathrm{nm}$ thickness or an aluminum top electrode of $100 \mathrm{~nm}$ thickness was evaporated on top of the photoactive layer. In addition, the $\mathrm{ZnO}$ layer $(25 \mathrm{~nm}$ ) (provided by NanoGrade, Lot \#5039), was bladed on top of the photoactive layer. After that, an aluminum top electrode of $100 \mathrm{~nm}$ thickness was evaporated. The typical active area of the investigated devices was $10.4 \mathrm{~mm}^{2}$. The current-voltage characteristics of the solar cells were measured under AM 1.5G irradiation on an OrielSol $1 \mathrm{~A}$ solar simulator $\left(100 \mathrm{~mW} \mathrm{~cm}^{-2}\right)$. The external quantum efficiencies (EQEs) were detected with a Cary 500 Scan UV-vis-NIR spectrophotometer under monochromatic illumination, which was calibrated with a mono-crystalline silicon diode. The characterization of the current density-voltage $(J-V)$ curve was done in an inert nitrogen atmosphere and the EQEs of the devices without encapsulation were measured in air.

AFM measurements were performed with a Nanosurf Easy Scan 2 in contact mode. Single carrier devices were fabricated and the dark current-voltage characteristics were measured and analyzed in the space charge limited (SCL) regime following ref. 7. The structure of hole only devices was glass/ITO/PEDOT:PSS/ active layer $/ \mathrm{MoO}_{3} / \mathrm{Ag}(100 \mathrm{~nm})$. For the electron only devices, the structure was glass/ITO/AZO/active layer/Ca (15 nm)/Ag (100 $\mathrm{nm}$ ), where both $\mathrm{Ca}$ and $\mathrm{Ag}$ were evaporated. The reported mobility data are average values over the six devices of each sample at a given film composition.

\section{Acknowledgements}

The authors would like to thank Dr P. V. Dmitryakov (the NBICS center of Kurchatov Institute, Moscow, Russia) for DSC and TGA measurements and S. M. Peregudova (the Institute of Organoelement Compounds of RAS) for CVA measurements. The authors gratefully acknowledge the support of the Cluster of Excellence "Engineering of Advanced Materials" at the University of Erlangen-Nuremberg, which is funded by the German Research Foundation (DFG) within the framework of its "Excellence Initiative". This work has been partially funded by the Sonderforschungsbereich 953 "Synthetic Carbon Allotropes”, the China Scholarship Council (CSC) and the Russian Scientific Foundation (RNF).

\section{References}

1 (a) V. Gupta, A. K. K. Kyaw, D. H. Wang, S. Chand, G. C. Bazan and A. J. Heeger, Sci. Rep., 2013, 3, 1965; (b) A. K. K. Kyaw, D. H. Wang, D. Wynands, J. Zhang, T.-Q. Nguyen, G. C. Bazan and A. J. Heeger, Nano Lett., 2013, 13, 3796.

2 A. K. K. Kyaw, D. H. Wang, V. Gupta, W. L. Leong, L. Ke, G. C. Bazan and A. J. Heeger, ACS Nano, 2013, 7, 4569.

3 J. Y. Zhou, Y. Zou, X. J. Wan, G. K. Long, Q. Zhang, W. Ni, Y. S. Liu, Z. Li, G. R. He, C. X. Li, B. Kan, M. M. Li and Y. S. Chen, J. Am. Chem. Soc., 2013, 135, 8484.

4 B. Walker, C. Kim and T. Q. Nguyen, Chem. Mater., 2010, 23, 470.

5 J. Roncali, Acc. Chem. Res., 2009, 42, 1719.

6 Y. Z. Lin, Y. F. Li and X. W. Zhan, Chem. Soc. Rev., 2012, 41, 4245.

7 J. Min, Y. N. Luponosov, T. Ameri, A. Elschner, S. M. Peregudova, D. Baran, T. Heumüller, N. Li, F. Machui, S. Ponomarenko and C. J. Brabec, Org. Electron., 2013, 14, 219.

8 (a) J. Min, Y. N. Luponosov, A. Gerl, M. S. Polinskaya, S. M. Peregudova, P. V. Dmitryakov, A. V. Bakirov, M. A. Shcherbina, S. N. Chvalun, S. Grigorian, N. K. Busies, S. A. Ponomarenko, T. Ameri and C. J. Brabec, Adv. Energy Mater., 2014, 4, 1301234; (b) J. Min, Y. N. Luponosov, 
D. Baran, S. N. Chvalun, M. A. Shcherbina, A. V. Bakirov, P. V. Dmitryakov, S. M. Peregudova, N. Kausch-Busies, S. A. Ponomarenko, T. Ameri and C. J. Brabec, J. Mater. Chem. A, 2014, DOI: 10.1039/C4TA01933D; (c) J. Min, Y. N. Luponosov, Z.-G. Zhang, S. A. Ponomarenko, T. Ameri, Y. F. Li and C. J. Brabec, Adv. Energy Mater., 2014, DOI: 10.1002/aenm.201400816.

9 H. X. Shang, H. J. Fan, Y. Liu, W. P. Hu, Y. F. Li and X. W. Zhan, Adv. Mater., 2011, 23, 1554.

10 C. Q. Ma, M. Fonrodona, M. C. Schikora, M. M. Wienk, R. A. J. Janssen and P. Bauerle, Adv. Funct. Mater., 2008, 18, 3323.

11 C. H. Cui, J. Min, C. L. Ho, T. Ameri, P. Yang, J. Z. Zhao, C. J. Brabec and W. Y. Wong, Chem. Commun., 2013, 49, 4409.

12 S. L. Shen, P. Jiang, C. He, J. Zhang, P. Shen, Y. Zhang, Y. P. Yi, Z. J. Zhang, Z. B. Li and Y. F. Li, Chem. Mater., 2013, 25, 2274.

13 Y. Z. Lin, L. C. Ma, Y. F. Li, Y. Q. Liu, D. B. Zhu and X. W. Zhan, Adv. Energy Mater., 2013, 3, 1166.

14 Y. M. Sun, G. C. Welch, W. L. Leong, C. J. Takacs, G. C. Bazan and A. J. Heeger, Nat. Mater., 2012, 11, 44.

15 Y. S. Liu, Y. Yang, C. C. Chen, Q. Chen, L. T. Dou, Z. R. Hong, G. Li and Y. Yang, Adv. Mater., 2013, 25, 4657.

16 J. Y. Zhou, X. J. Wan, Y. S. Liu, Y. Zou, Z. Li, G. R. He, G. K. Long, W. Ni, C. X. Li, X. C. Su and Y. S. Chen, J. Am. Chem. Soc., 2012, 134, 16345.
17 W. W. Li, M. Kelchtermans, M. M. Wienk and R. A. J. Janssen, J. Mater. Chem. A, 2013, 1, 15150.

18 T. S. van der Poll, J. A. Love, T. Q. Nguyen and G. C. Bazan, Adv. Mater., 2012, 24, 3646.

19 Y. S. Liu, C.-C. Chen, Z. R. Hong, J. Gao, Y. M. Yang, H. P. Zhou, L. T. Dou, G. Li and Y. Yang, Sci. Rep., 2013, 3, 3356.

20 D. Demeter, V. Jeux, P. Leriche, P. Blanchard, Y. Olivier, J. Cornil, R. Po and J. Roncali, Adv. Funct. Mater., 2013, 23, 4854.

21 E. Ripaud, T. Rousseau, P. Leriche and J. Roncali, Adv. Energy Mater., 2011, 1, 540.

22 Z. G. Zhang, S. Y. Zhang, J. Min, C. H. Chui, J. Zhang, M. J. Zhang and Y. F. Li, Macromolecules, 2012, 45, 113.

23 S. Y. Ma, Y. Y. Fu, D. B. Ni, J. Mao, Z. Y. Xie and G. L. Tu, Chem. Commun., 2012, 48, 11847.

24 S. A. Ponomarenko, N. N. Rasulova, Y. N. Luponosov, N. M. Surin, M. I. Buzin, I. Leshchiner, S. M. Peregudova and A. M. Muzfarov, Macromolecules, 2012, 45, 2014.

25 J. Min, Z. G. Zhang, M. J. Zhang and Y. F. Li, Polym. Chem., 2013, 4, 1467.

26 C. J. Brabec, A. Cravino, D. Meissner, N. S. Sariciftci, T. Fromherz, M. T. Rispens, L. Sanchez and J. C. Hummelen, Adv. Funct. Mater., 2001, 11, 374.

27 R. Alvarez and G. H. Mehl, Tetrahedron Lett., 2005, 46, 67. 